\title{
RACISMO, RACISMOS: AINDA HÁ MUITO QUE DIZER
}

BETHENCOURT, Francisco. Racismos: das cruzadas ao século XX. São Paulo: Companhia das Letras, 2018. 603 p.

$F_{\text {rancisco Bethencourt não é his- }}$ toriador de poucas palavras, embora seus livros, dois já publicados no Brasil, ainda que extensos, não sejam cansativos. ${ }^{1}$ Demonstrando que a erudição não precisa ser enfadonha, temos na obra aqui resenhada uma escrita fluente, marcada por um texto sem rodeios, preciso e fluido. Isto se verifica ainda mais nos capítulos que, abordando períodos mais recentes e contemplando realidades não europeias, se distanciam daquilo com que o autor é mais familiarizado.

Comecemos pelo nome da obra: Racismos. A abrangência temporal e espacial da análise - das Cruzadas ao século XX - facilmente explicaria o porquê do plural. O historiador quis avisar ao leitor, desde o título,

1 Cf. Francisco Bethencourt. História das Inquisições. Portugal, Espanha e Itália. Séculos XV-XIX. São Paulo: Companhia das Letras, 2000; bem como Francisco Bethencourt, $O$ imaginário da magia: feiticeiras, adivinhos e curandeiros em Portugal no século XVI. São Paulo: Companhia das Letras, 2004. que não há uma história linear $\mathrm{e}$ cumulativa de um tipo, apenas, de "racismo", não sendo inato à condição ou natureza humana. Fundamentado no preconceito de superioridade étnica associado a alguma forma de discriminação, o racismo é antes um fenômeno histórico, ou seja, contextual, marcado pelas relações construídas em determinado tempo e lugar. $\mathrm{O}$ racismo tem sido parte de projetos políticos que culminaram em regimes de segregação ou até de genocídio, no entanto há exceções. Muitas foram as formas de racismo, não só baseado na cor da pele das pessoas ou como produto das teorias raciais.

Dividido em cinco partes, além da "Introdução" e "Conclusões", temos então grandes contextos amalgamados pela expansão europeia:

1. A primeira parte, "As Cruzadas", compreende quatro capítulos: "Das percepções gregas às muçulmanas"; "Reconquista cristã"; "Universalismo: Integração e classificação": e "Tipologias da humanidade 
e modelos de discriminação".

Nesta primeira parte, o autor traz algumas ideias importantes. Aponta, na Antiguidade Clássica, a crença entre gregos e romanos letrados de que "as características físicas e mentais dos seres humanos eram moldadas por fatores externos" (p. 37). Associada à tese de determinismo ambiental, haveria a "noção de características hereditárias adquiridas por seres humanos" (p. 38), ou seja, "o fato de o preconceito no mundo grego e romano já estar associado à noção de linhagem e ascendência" (p. 39). No império romano, cujo acesso à cidadania conheceu uma abrangência inexistente entre os gregos antigos, o universalismo político imperial tinha um peso importante, não havendo critérios raciais ou étnicos necessariamente impeditivos à cidadania. A própria escravidão, base de sustentação do império romano, elegia como critério de escravização a condição de prisioneiros de guerras, além, obviamente, do ventre escravo, ainda que houvesse certa predileção pelos povos de ascendência oriental.

$\mathrm{Na}$ Idade Média, com a universalização religiosa do cristianismo, de um lado, e do islamismo, de outro, se manteve a tensão entre universalismo e preconceito étnico, ainda que a cor da pele não tivesse peso considerável. Com a redescoberta dos autores da antiguidade greco-romana, foram retomadas as noções de preconceito baseadas no determinismo ambiental e características adquiridas pela hereditariedade. Os elementos de linhagem e ascendência já existentes no mudo greco-romano não haviam de desaparecer no período medieval. Nos territórios da Península Ibérica, Sicília e Oriente Médio, que conheceram a reconquista e o domínio do cristianismo - nos dois primeiros de forma mais efetiva e permanente - , o universalismo cristão, implicando conversão e assimilação, se configurava a partir de uma "associação hierárquica" (p. 67) com as populações árabes e judias, unindo-se ao preconceito étnico inclusive no mundo cristão oriental sob o império bizantino.

Ainda sobre esse período, Bethencourt diz que "Dante foi um dos primeiros autores medievais a diferenciar os tipos humanos segundo o conceito de continentes: asiáticos, africanos e europeus" (p. 83), além de indicar a associação dos preconceitos com a aparência física: "A cor da pele não era irrelevante. A vasta gama de cores - branco, castanho-claro, castanho-escuro e preto - representada em vários manuscritos indica a percepção das diferentes compleições" (p. 88), embora o preconceito de cor não fosse tão óbvio. Ele analisa também o desprezo étnico, inclusive entre povos cristãos, e a relação entre conversão religiosa e estigma, como no caso de judeus e muçulmanos, já discriminados segundo a "ideia de ascendência" (p. 98), além da religião.

$\mathrm{O}$ autor termina essa parte mostrando que as noções de preconceito oriundas da antiguidade greco-romana foram reelaboradas por autores ligados ao cristianismo e ao islamis- 
mo. No medievo, na Península Ibérica cristã, em particular, a religião e os preconceitos com base na ascendência étnica começaram a se misturar a partir da ideia de pureza de sangue. Concebendo os preconceitos sempre como relacionais, portanto historicamente construídos, o preconceito contra os negros na região do Mediterrâneo, de alguma forma já existente na Antiguidade Clássica, haveria de persistir, renovados no medievo por parte de letrados muçulmanos ou cristãos, "antecipando", segundo o autor, "o desprezo generalizado desencadeado pelo aumento do comércio escravagista da África para a Europa, e depois para a América, nos séculos seguintes" (p. 98).

2. "Exploração oceânica". Esta é a segunda parte do livro, com cinco capítulos. Aqui o autor segue três linhas de inquérito: a primeira sobre os motivos para o paradoxo entre o reconhecimento da diversidade humana no cerne da Renascença e a "classificação das diferentes partes do mundo" (p. 100) como resposta à ampliação e diversidade do mundo conhecido, e sobretudo suas gentes, pelos europeus. Estes, diante desse quadro maior, se definiram como brancos. A segunda linha trata da "evolução dos critérios empregados para a identificação dos povos do mundo" (p. 100). A terceira tem como eixo o "papel da ascendência e da divisão entre castas" (p. 101).

No rastro da expansão europeia, o autor dedica capítulos separados para africanos, americanos (no sentido de povos originários do "Novo
Mundo"), asiáticos, além dos próprios europeus. Noções de pureza de sangue, ascendência e preconceito de origem étnica, associadas à cor da pele ganham relevância. Apesar do universalismo presente na perspectiva do Humanismo, as visões sobre diferenças entre os povos agudizam e se apresentam numa escala de hierarquias da qual os europeus assumem o topo. Enfim, o largo uso da escravidão no Novo Mundo, num primeiro momento dos índios, depois dos africanos, contribui para o amálgama dos preconceitos de ascendência étnica e cor da pele. Já no século XVIII, lembra-nos o autor, tiveram origem as teorias raciais, ao passo que também se verificou o surgimento da crítica abolicionista ao tráfico de escravos e à escravidão (p. 144). Teorias raciais e abolicionismo que desde então haveriam de caminhar juntos, ainda que numa relação não destituída de tensões. Segundo o autor, "os estereótipos cristãos em relação aos africanos negros, que durariam até o século XX", a partir de um rol de defeitos atribuídos, eles "foram usados para justificar três séculos e meio de comércio escravagista atlântico e a partilha da África na década de 1880" (pp. 130-131).

Nesta parte, Bethencourt aponta algo importante: a partir da expansão cristã europeia, "os preconceitos podem ser ocultados ou ativados, de acordo com conjunturas específicas determinadas pelo comércio, pela evangelização ou pelos projetos imperiais" (p. 124). Neste sentido, ele propõe uma história social e cultural 
do racismo, detalhando personagens, situações ou contextos históricos que nos permitem ver relações que ocultam ou ativam preconceitos. Como ao longo de todo o livro, a bibliografia mobilizada é vasta, mas no caso português, por exemplo, senti a falta do trabalho de Didier Lahon. ${ }^{2}$ Outra ausência notável é Sérgio Buarque de Holanda, em particular Visão do paraíso, estudo comparativo clássico das visões castelhanas e lusitanas sobre o Novo Mundo e seus habitantes originários. ${ }^{3} \mathrm{De}$ fato, ainda que trate várias vezes das realidades luso-brasileira e brasileira ao longo do livro, Bethencourt passa ao largo de parte significativa da nossa historiografia, mesmo considerando esta uma obra de caráter mais geral.

No último capítulo desta parte, acerca dos europeus no sul do continente, o autor aborda o tratamento recebido pelos mouriscos (muçulmanos convertidos ao cristianismo), no qual se distancia da leitura braudeliana sobre o estranhamento da comunidade mourisca no seio da sociedade cristã ibérica como resultado unicamente da

2 Por exemplo, Didier Lahon, O negro no coração do Império: uma memória a resgatar: séculos XV a XIX, Lisboa: Ministério da Educação, 1999; bem como Didier Lahon, "Esclavage et confréries noires au Portugal durant l'Ancien Régime (1441-1830)" (Tese de Doutorado, École des Hautes Études en Sciences Sociales, 2001).

3 Sérgio Buarque de Holanda, Visão do paraíso: os motivos edênicos no descobrimento e colonização do Brasil, São Paulo : Companhia das Letras, 2010. questão religiosa, apontando a importância do preconceito étnico, ou seja, a atribuição à população mourisca de características imaginadas para os muçulmanos, apesar da conversão ao cristianismo. Também trata dos chamados cristão novos (judeus convertidos ao cristianismo), bem como dos judeus propriamente, além dos ciganos, demonstrando a importância dos preconceitos étnicos fundamentados na ideia de pureza de sangue ou ascendência, não apenas a religiosa. Neste ponto, o autor demonstra em maior detalhe o tratamento dado aos mouriscos e cristãos novos como "casos claros de racismo" (p. 213), definido este "no sentido de preconceitos contra a ascendência étnica, combinando com ações discriminatórias" (p. 221). Lembra, igualmente, serem os ciganos "um caso importante de discriminação étnica não baseada no conflito religioso, pois os ciganos (romani) eram cristãos, mas sim no modo de vida e na ascendência", havendo ainda, por exemplo, mais ao norte da Europa, o caso dos lapões, alvo de visões preconceituosas por conta de seu modo de vida.

Neste momento do livro, já está devidamente referenciado pelo historiador a constatação de que o racismo não pode ser, nem nunca foi, uma prática unicamente baseada na discriminação pela cor da pele. Tanto que havia discriminação contra judeus, cristão novos, mouriscos, ou ainda povos da periferia política da Europa, como os irlandeses ou eslavos, todos vítimas de racismo, apesar de serem todos classificados como brancos. 
Nesta parte da obra, bem como na terceira - porém menos nesta -, Bethencourt está mais confortável em seu elemento devido à sua larga experiência de historiador da modernidade. Não poderia ser diferente. Não estranha, aliás, que as duas partes consumam mais da metade do livro. Ao mesmo tempo, até se justificaria essa largura por se tratar de um momento crucial para entender a formação do racismo - ou "racismos" - entre os europeus. Ainda que a associação do racismo com ideias de pureza de sangue e ascendência étnica, conjugadas à cor da pele, não fosse novidade, já existindo de alguma forma em períodos anteriores, foi a partir das explorações oceânicas e o largo uso da escravidão no Novo Mundo que o preconceito de cor ganhou importância. Neste momento, então, adentramos a discussão sobre as sociedades coloniais:

3. A terceira parte do livro discute a etnogênese nas sociedades coloniais nos continentes americano, africano e asiático, sob o impacto da expansão europeia. $\mathrm{O}$ autor diverge da teoria de transmissão das características nacionais dos países conquistadores/colonizadores para as sociedades coloniais então gestadas, se distanciando, por exemplo, do britânico Niall Fergunson, criticando o historiador, que "toma o pressuposto básico do "ser britânico' como dado” (p. 541, nota 4). ${ }^{4}$

4 Cf. Niall Ferguson, Império: como os britânicos fizeram o mundo moderno, São Paulo: Crítica, 2017.
Bethencourt aponta como um erro dessa abordagem essencialista deixar os nativos de fora do processo de constituição das sociedades coloniais. Em suma, o autor tem aqui como objetivo "estudar os novos preconceitos étnicos suscitados pela criação de sociedades coloniais europeias" (p. 226), ou seja, demonstrar como "os empreendimentos coloniais influenciaram os preconceitos étnicos e raciais" (p. 227).

São cinco capítulos: "Classificação étnica"; "Estrutura étnica"; "Projetos e políticas"; "Discriminação e segregação" e "Abolicionismo". No primeiro, o autor discute como se deu a construção de uma classificação étnica sobre os diversos povos atingidos pela expansão europeia, particularmente diante da mestiçagem daí surgidos. Haveria a necessidade de inquirir, conhecer, inventariar, classificar, padronizar, na medida do possível e desejável, enfim, hierarquizar as diversas gentes e mestiçagens como parte das estruturas de poder. No caso das sociedades americanas, que nos interessa mais de perto, o pesquisador discorre sobre as categorias mestiças, origens dos termos e seus usos sociais, enfatizando não ser a mestiçagem apenas um dado biológico. Discorre, então, sobre crioulos, mulatos, pardos, morenos, mamelucos, caboclos, carijós, curibocos e cafuzos. No caso desta última categoria social, me interessa dizer algo mais.

Nascidos da relação entre negros e índios, cafuzo, nos diz o autor, era 
termo recorrente no Brasil oitocentista, o qual "provavelmente se inspirou no quimbundo kufunzaka, que significa descolorir e que revela a visão africana do processo de mistura racial” (p. 242). A citada inspiração esta referendada no dicionário Houaiss de língua portuguesa. Mas não unicamente. Talvez por isso o autor apontou que em Luanda, no século XVIII, além dos termos branco, mulato e negro, outras duas categorias eram conhecidas: "cabrito (filho de branco e mulato com pele escura mais clara) e cafuzo (filho de mulato com negro)", lembrando, então, "a adaptação posterior de cafuzo no Brasil, onde passou a ser usado para indicar filho de índio e negro" (p. 247). De qualquer modo, é preciso dizer que o termo "cafuzo" já existia no Brasil desde antes do século XIX. Seu uso não seria tão comum em todo o país, mas bastante usual na Amazônia portuguesa, conhecendo variações: cafuz, carafus ou carafuso, sendo a denominação corrente para o filho de negros e índios de cor mais escura e cabelos lisos. Vicente Salles já apontou para a etimologia controvertida da palavra "cafuz" referenciada em vários autores, reconhecendo a possibilidade de que o "quimbundo consigna os vocábulos Kifusu, Kifusa, e Kaufusa, que podem, talvez, encerrar o étimo procurado."

Vicente Salles, Vocabulário crioulo: contribuições do negro ao falar regional amazônico, Belém: Instituto de Artes do Pará/IAP, Programa Raízes, 2003, pp. 105-106.
Pode-se dizer que, num livro abrangente como este, a discussão das mestiçagens na América portuguesa não permite certas especificidades, como a que se aponta aqui sobre os cafuzos na região amazônica, extensa área que já foi considerada por José Veríssimo, em fins do século XIX - e antes dele por vários viajantes estrangeiros no Oitocentos -, um laboratório de tipos sociais mestiços. ${ }^{6}$

Bethencourt demonstra que, com a expansão europeia, "as características fenotípicas tornaram-se aspecto essencial para a definição dos diferentes tipos de humanidade" ( $p$. 149). Dando conta da composição étnica dos mundos coloniais, particularmente nas Américas, nos diz que os "principais sistemas de categorização baseavam-se na cor da pele, pois era simples de usar e não contemplavam exceções" (p. 280). Conclui, então, que por conta dessa realidade, "a história da raça suplantou a história da linhagem e da etnia; esta era muito mais complexa, baseando-se na migração constante, na recomposição e na fluidez de alianças" (p. 280). Tornava-se a cor da pele um parâmetro para projetos e políticas de controle colonial pelos europeus nas Américas e, poste-

6 Embora citado em outros momentos do livro, a respeito da conquista colonial, conferir p. 160; ainda sobre a mestiçagem, penso que faz falta referência ao trabalho de Serge Gruzinski, especificamente sobre o tema. Cf. Serge Gruzinski, O pensamento mestiço, São Paulo: Companhia das Letras, 2001. 
riormente, nos demais continentes. Neste sentido, Bethencourt trata sobre discriminação e segregação como parte dos projetos e políticas coloniais europeias para populações indígenas e africanas nas Américas, sem negligenciar as dinâmicas internas dessas sociedades, principalmente na América portuguesa, bem menos presente nas Américas inglesa e holandesa.

A terceira parte fecha com um capítulo sobre o abolicionismo. Uma síntese perfeita e bem construída do alcance e das limitações desse movimento que, embora antiescravista, era marcado por preconceitos raciais da parte de seus protagonistas. Daí o autor dizer muito acertadamente que: "A extensão dos direitos humanos a todas as raças como ideal e prática política não aconteceu nem durante o período de revoluções nem no longo século XIX” (p. 333), e concluir, com mais razão, que: "A inclusão progressiva de outras raças nos direitos humanos foi um processo longo e demorado" (p. 333), podendo ser dito que ainda está longe de ser alcançado no século XXI, apesar dos avanços. Nesse ponto, tratando das relações entre abolicionismo e teorias raciais, o autor adentra a quarta parte do livro.

4. Não poderia deixar de haver neste livro uma parte destinada à análise das teorias raciais ou teorias sobre as raças. Nesta, temos três capítulos: "Classificações dos seres humanos"; "Racialismo científico"; e "Darwin e a evolução social". O autor prefere o uso do termo "racialismo científico" ao invés de "racismo científico", por entender que as teorias de raça não fundam o racismo, ainda que seja parte importante de sua história social e intelectual. ${ }^{7}$ Até porque, o autor vem demonstrando que os preconceitos étnicos, associados à ancestralidade e à linhagem, bem como ao ideal de pureza de sangue, ganhando com o escravismo colonial uma conotação cada vez mais forte em torno à cor da pele, antecederiam as teorias de raça, ainda que a conceituação do termo "raça" somente viesse a ser contemplado justamente com as "teorias racialistas". Concordando ou não com Bethencourt - não necessariamente concordo com os termos que propõe -, não resta dúvida que, ao abordar esse período o autor nos permite conhecer mais uma vez sua erudição, escrevendo não somente uma história intelectual das teorias racialistas, mas igualmente uma história ideológica, política e social do racismo.

Teorias racialistas ou raciais que, embora muito conhecidas por nós a partir dos intelectuais ocidentais, também existiram entre intelectuais não ocidentais, a exemplo dos japoneses, para justificar o expan-

7 Lembrando aqui, no entanto, que racialismo ou teorias racialistas, entre outros similares, já são termos consagrados pela antropologia e os historiadores do pensamento racial nos últimos tempos. Ver a respeito, por exemplo, os trabalhos de Lilia Schwarcz e Antônio Sérgio Guimarães. 
sionismo imperialista de seu país no século XX. A associação do nacionalismo a preconceitos étnicos e raciais contra demais povos asiáticos nos leva para a última parte do livro, "Nacionalismo e mais além".

5. A quinta e última parte se compõe de apenas dois capítulos: "O impacto do nacionalismo" e "Comparações globais". No primeiro, acerca do nacionalismo e suas relações com os preconceitos étnicos, assentados em políticas discriminatórias e às vezes segregacionistas, o autor discute o caso armênio, "primeiro exemplo de um genocídio programado cometido por um Estado [a Turquia] contra uma minoria nacional específica." Já não se tratava de "comunidades vulneráveis abandonadas por um Estado que não conseguia (ou não queria, como no caso da Rússia) garantir proteção e segurança" (p. 434), e sobre a Rússia ele tem em mente os judeus alvos dos pogroms na era czarista. Segundo o historiador: "Em vários aspetos os Jovens Turcos estabeleceram um precedente para a Alemanha nazista, baseado na fusão dos conceitos de nação e de raça, ao visarem a deportação e exclusão física a toda uma etnia considerada uma nação rival que não deveria partilhar o mesmo território" (p. 436). Passa, então, o autor a tratar do holocausto. Considerando a Alemanha nazista como "o caso em que mais completamente se assistiu à aplicação política das teorias raciais" (p. 445), faz uma síntese competente do genocídio praticado pelo regime de Hitler.
No segundo capítulo, "Comparações globais", além da análise da realidade europeia em torno das deportações, migrações forçadas e trabalho escravo, o autor discorre sobre discriminação e segregação nas Américas, particularmente as políticas racistas nos estados do Sul dos Estados Unidos, do Apartheid e genocídios no continente africano, sem deixar de atentar para a realidade asiática. Ou seja, o século XX, ao seu término, ainda seria fortemente marcado por políticas e projetos de poder baseados no preconceito étnico ou, simplesmente, no racismo. Apesar dos avanços.

Queria, antes de concluir, tecer um comentário sobre o uso de fontes iconográficas, método que ainda engatinha em nossa historiografia. Ao longo do livro, as imagens são fontes discursivas importantes para, e na, construção dos argumentos do autor, que analisa esculturas, iluminuras, pinturas, gravuras, fotografias etc.

Como discorrer, por exemplo, na Parte II, sobre as hierarquias de continentes e povos (africanos, americanos, asiáticos e europeus), construídas em sociedades largamente iletradas, sem o recurso à análise das imagens da época? O capítulo "Hierarquias de continentes e povos" é um primor em termos de leitura das fontes iconográficas. Não à toa que somente neste capítulo tenhamos seis figuras muito bem distribuídas ao longo do texto e admiravelmente interpretadas pelo historiador. No capítulo seguinte, quando tra- 
ta das imagens construídas acerca dos africanos, Bethencourt analisa nove figuras. No capítulo sobre os povos americanos, faz uso de sete imagens. Quatro figuras aparecem e são destrinchadas no capítulo sobre os asiáticos. Apenas duas imagens são trabalhadas no capítulo acerca dos europeus. Lamenta-se, contudo, que elas sejam reproduzidas apenas em preto e branco, pois cor, quando há, pode permitir o vislumbre de aspectos fundamentais da produção, emissão e percepção, além do contexto histórico, das imagens.

Sente-se também falta, em alguns momentos, de ainda mais iconografia, uma vez que, além das ali publicadas, Bethencourt se refere a outras tantas que não o foram. Pois nem sempre é suficiente a descrição das imagens feita pelo narrador. $\mathrm{Na}$ primeira parte do livro, por exemplo, Bethencourt lança mão de oito fontes iconográficas, distribuídas entre os capítulos. Lembro aqui o caso, no capítulo 2, quando, comentando a escultura que sustenta o primeiro sarcófago do rei cristão Rogério II, da Sicília, reproduzida no livro, inclusive em detalhe (figuras 2.1.A e 2.1.B), ele a compara com a escultura que sustenta o segundo sarcófago do dito rei, apenas descrita pelo autor, mas não reproduzida por alguma razão no livro. ${ }^{8}$

Além de imagens, o autor faz uso muito interessante de mapas, que se casam perfeitamente com a narrativa textual, cumprindo um papel informativo e interpretativo, complementares ao texto.
Bethencourt termina seu livro com a certeza de que conseguiu comprovar sua hipótese de que "o racismo foi motivado historicamente por projetos políticos" (p. 496). Mesmo que não se concorde totalmente com essa premissa - afinal o racismo pode existir como práxis social, apesar de criminalizado pelo Estado e publicamente rejeitado por setores da sociedade, como no caso brasileiro -, tal premissa é justamente importante na medida em que desnaturaliza qualquer noção de racismo como próprio da condição humana. Racismo é uma ação política, inclusive no campo da micropolítica das relações humanas.

Outra afirmação importante é que o racismo precedeu as teorias sobre a desigualdade das raças surgidas no século XIX. Neste ponto, creio que a contribuição deste livro se torne ainda mais importante, ao criticar a assertiva consagrada de que o racismo científico cunhou o racismo moderno, assentado nos preconceitos racial e étnico, enquanto no passado haveria o racismo de base religiosa. Da mesma forma, demonstra-nos outros aspectos importantes da questão: a irredutibilidade do racismo unicamente aos preconceitos de cor, até porque sua identificação nessa chave somente ganhou importância no mundo moderno a partir da expansão europeia. Nesse sentido, no século $\mathrm{XX}$, se a cor da pele determinava as políticas raciais no Sul dos EUA, por exemplo, o preconceito racial contra os judeus brancos na Europa, particularmente 
na Alemanha nazista, não se fundamentava na cor da pele. No caso do Brasil, ao contrário dos EUA, a cor da pele teria uma definição mais social, ou seja, pessoas não brancas são embranquecidas socialmente em razão de seu status ou riqueza, ainda que o racismo em relação a elas esteja sempre à espreita. Eis o lado cínico e perverso do racismo no Brasil, uma vez que, para que negros sejam ou possam ser respeitados e feitos cidadãos plenos precisam ter grana ou fama.

Outro ponto importante, que a abrangência temporal e espacial do livro permite perceber, é a compreensão de que o racismo não é uma característica tão somente do mundo ocidental. $\mathrm{O}$ autor mostra sua vigência em países do Oriente, por exemplo, como China, Japão e Índia, ou ainda algumas situações envolvendo países e sociedades africanas. Demonstrando, assim, a necessidade de se olhar para além do Ocidente na discussão sobre o racismo.

Enfim, a principal ideia desenvolvida pelo autor foi bem demonstrada, ou seja, "o racismo assumiu diferentes formas, moldadas por conjunturas específicas", não existindo "algo como um racismo cumulativo e linear" (p. 508), pois acreditar nisto seria naturalizar e despolitizar o debate em torno deste fenômeno. O livro ajuda a desconstruir a velha argumentação de que "o mundo desde que existiu....". Temos que concordar com Francisco Bethencourt sobre ser ainda preciso "percorrer um longo caminho para cumprir o sonho da dignidade humana e da real implementação dos direitos humanos" (p. 509).

José Maia Bezerra Neto jmbn25@gmail.com Universidade Federal do Pará 